\title{
Implicit and explicit memory for compound words
}

\author{
MARK TIPPENS REINITZ \\ Boston University, Boston, Massachusetts \\ and \\ JONATHAN B. DEMB \\ Stanford University, Stanford, California
}

\begin{abstract}
Subjects studied visually presented compound words (e.g., TOOTHPASTE, HEARTACHE) and then received a recognition, perceptual identification, or word-fragment completion test that contained old, recombined (e.g., TOOTHACHE), and partially and completely new words. False recognitions increased with the increasing number of previously studied components; however, priming in perceptual identification occurred only for old words. Priming in word-fragment completion occurred for old and recombined words. Reducing the time available to solve word fragments, from $20 \mathrm{sec}$ to $5 \mathrm{sec}$, did not affect the pattern of results; it is therefore unlikely that priming for recombined words resulted from the use of a recollection-based strategy. Memory tasks that involve a conceptual component access memories that are constructed from parts; memory tasks that are primarily perceptual do not access such memories.
\end{abstract}

Reinitz, Lammers, and Cochran (1992) demonstrated that subjects will often claim to have seen a new stimulus if it is constructed from parts of previously studied stimuli. In their experiments, subjects studied visually presented faces or two-syllable nonsense words and then received a recognition test containing four types of test stimuli-old stimuli, which had been presented during study; conjunction stimuli, which were constructed by recombining features of separate study stimuli; feature stimuli, which contained half old and half new features; and new stimuli, which contained only new features. For both stimulus types, the false alarm rate was greater for conjunction than for feature stimuli, which in turn did not differ very much from the false alarm rate for new stimuli. Additionally, Reinitz et al. (1992) demonstrated that conjunction errors occur much more frequently than feature errors do in free recall. The recognition findings were replicated for faces by Reinitz, Morrissey, and Demb (1994), who compared recognition memory for faces studied under full- and divided-attention conditions. The effect of dividing attention was essentially to make old and conjunction stimuli indistinguishable from one another during the recognition test. The divided-attention subjects responded that old and conjunction faces were

We thank Rebecca Alexander, Jodie Roberts, Tom Dyar, Melinda Kuriger, Joe Morrissey, Laura Pharaon, Yagi Tramontini, and Karen Venneri for running the subjects and for their many helpful comments. We also thank John Gabrielli, Jackie Liederman, Geoff Loftus, Cindy Thomsen, and two anonymous reviewers for their comments and suggestions. Correspondence regarding the article should be addressed to M. T. Reinitz, Department of Psychology, Boston University, 64 Cummington St., Boston, MA 02215 (e-mail: markr@acs.bu.edu). "old" approximately equally often, and they were less likely to respond that feature or new faces were old. Together, these studies indicate that explicit memories are constructed from stored stimulus features, and that attention is important for encoding the relational information necessary to guide their construction. False alarms to conjunction stimuli are proposed to occur when features residing in memory are incorrectly conjoined at the time of recollection, resulting in "memories" for stimuli that had not been previously experienced.

Reinitz and his colleagues demonstrated that the memories that underlie performance on recognition and recall tests possess an underlying parts structure; that is, they are constructed from stored parts that represent stimulus components. Recognition and recall are both examples of explicit memory tests, because subjects must intentionally attempt to remember the previous study episode. These can be contrasted with implicit tests, in which subjects do not need to intentionally access the contents of memory. Rather, the presence of an item in memory is indicated by priming - that is, by performance for previously presented items that is superior to that for new items on some task. The distinction between explicit and implicit memory is currently a central topic in memory research because of the many well-known dissociations between performance on the two types of tasks. The purpose of the present study was to test whether the pattern of results observed by Reinitz and his colleagues on explicit memory tasks also occurs on implicit tasks.

Two commonly used implicit memory tests are perceptual identification and word-fragment completion. In perceptual identification tests, subjects attempt to iden- 
tify masked, briefly presented stimuli. Identification performance is typically better for previously presented words than for new words. Word-fragment completion entails presenting words with several of the letters deleted; subjects have a limited time to attempt to discern the word from the fragment. Again, fragments of previously viewed words are more likely to be solved than are fragments of new words. Both of these tasks are commonly used to demonstrate dissociations between implicit and explicit memory performance. If implicit test performance depends on memories that are represented as sets of parts, then priming should occur for conjunction words on these tests. It is important to test whether such priming occurs, because the finding of an underlying parts structure for explicit memories is so salient across so many types of stimuli that it seems to constitute a general rule. An underlying parts structure has been demonstrated on explicit tasks using stimuli for which memory is likely to be primarily semantic, such as sentences (Reinitz et al., 1992, Experiment 2) and words on "the tip of the tongue" (Brown \& McNeill, 1966) as well as for memories that are likely to be primarily perceptual, such as recognition of faces (Reinitz et al., 1992; Reinitz et al., 1994) and recollection of abstract visual patterns (Kosslyn, Cave, Provost, \& von Gierke, 1988). Dissociations between implicit and explicit tasks have been proposed by some authors to result from the relation between the type of encoding at study and the informational demands of the memory test (e.g., Roediger, 1990; Snodgrass \& Luo, 1993). If this process-specificity explanation is correct, then memories involved in both implicit and explicit test performance might be expected to obey the general rule of having a parts structure. Other authors (e.g., Squire, 1992; Tulving \& Schacter, 1990) have proposed that dissociations between tasks reflect independent implicit and explicit memory systems. If so, there is no reason to expect that implicit and explicit memories should be structurally similar.

Findings from previous research are ambiguous regarding whether implicit memories have underlying parts structures. Arguing against the proposal of underlying parts structures are many studies indicating that small surface changes in stimuli at the time of test can greatly reduce or even eliminate priming on implicit tests (e.g., Jacoby \& Hayman, 1987; Roediger \& Blaxton, 1987; Warren \& Morton, 1982). Recombining stimulus parts at test represents a large surface change relative to these examples; the finding of priming for conjunction words would therefore be surprising. However, at least one study has indicated that implicit memories are composed of parts (Musen \& Squire, 1993). In Musen and Squire's study, amnesic patients and nonamnesic controls studied a series of visually presented stimuli that were constructed by concatenating two short words (e.g., gumpark, jamdirt). For both groups, performance for recombined word pairs (e.g., gumdirt) was better than that for completely new pairs in a subsequent perceptual identification test. This result is consistent with the proposal that implicit memories for previously experienced stimuli are constructed from parts. However, it is important to note that the concatenated words held no relation to one another. The subjects may therefore have perceived the stimuli as word pairs, rather than as single, intact stimuli. If each word of the pair were perceived separately, it would not be surprising that each word should have its own memory representation. It is unclear whether similar results would be found for stimuli that are likely to be perceived as unitary entities possessing a single underlying meaning. Indeed, Musen and Squire interpret their result as indicating their subjects' failure to implicitly learn associations, rather than as evidence that implicit memories are constructed from underlying parts.

In the present experiments, subjects studied a series of compound words (e.g., EYELID, wINEGLASS) and then received a recognition, a perceptual identification, or a word-fragment-completion test. Each memory test contained old, conjunction (e.g., EYEGLASS), feature, and new words. If both explicit and implicit memories for compound words are constructed from parts, there should be more false alarms to conjunction stimuli than to feature or new stimuli in the recognition test; additionally, priming should be observed for conjunction words on the perceptual identification and word-fragment-completion tests. However, if only explicit memories are constructed from parts, no priming should be observed for conjunction stimuli on the implicit tests.

\section{EXPERIMENT 1}

The subjects in Experiment 1 studied a series of visually presented compound words. Then they received either a recognition test or a perceptual identification test containing old, conjunction, feature, and new words.

\section{Method}

Subjects. Eighty-four Boston University undergraduates participated for course credit. They were run in 28 groups, each containing 3 subjects.

Stimuli and Apparatus. The study and test stimuli were photographic slides of 84 compound words. Fifty-six words were paired so that the first segment of the first word in the pair and the second segment of the second word in the pair made a novel compound word when combined (e.g., TOOTHPASTE-HEARTACHE; TOOTHACHE). This resulted in 28 additional (conjunction) words. The complete stimulus set is presented in the Appendix. The words subtended about $7^{\circ}$ of visual angle horizontally and about $0.75^{\circ}$ vertically. A mask consisted of a jumble of straight and curved black lines; it subtended about $10^{\circ}$ vertically, and about $15^{\circ}$ horizontally. Stimulus and mask luminances were displayed so that when both were presented simultaneously, it was impossible to read the word. All the stimuli were presented with Kodak slide projectors equipped with Gerbrands tachistoscopic shutters. The projectors and shutters were controlled by an IBM AT-compatible computer, and timing was controlled by a clock card in the computer.

Design and Procedure. Each group of subjects was presented with 16 study words for $1.5 \mathrm{sec}$ each. There was a 7 -sec interstimulus interval between study stimuli. A beep was presented 1 sec before each study word; this indicated that the subjects should fixate on the screen. The subjects were told to view each word and that they might receive a memory test for the words. 
Following the study session, the subjects received a mental rotation test. This filler test took about $15 \mathrm{~min}$. The subjects then received a memory test that involved the presentation of 16 test stimuli. Fourteen groups received a recognition test, and 14 received a perceptual identification test. For each group that received the recognition test, there was a perceptual identification group that received the identical study and test stimuli in the identical order. Of the 16 test words, 4 were old stimuli that had been presented during study. Four test words were conjunction stimuli. Four test words were feature stimuli that were made up of a studied word segment and a novel word segment; 2 were comprised of a novel first segment and a studied second segment, and 2 of a studied first segment and a novel second segment. Finally, there were 4 new test stimuli, which had not been studied. Fourteen random study and test orders and 14 unique sets of study and test stimuli were used across the groups.

Each test stimulus occurred in each of the test conditions equally often. Additionally, when used as a feature stimulus, each test word contained the first syllable of a previously studied word and the last syllable of a previously studied word equally often. For the recognition test, words were presented for $3 \mathrm{sec}$ each, with a $9-\sec$ interstimulus interval. The subjects made old/new judgments for each word by circling the words old or new on their response sheets. They were told to respond "old" only if they were sure that the word had been presented during study. In the perceptual identification test, words were presented for $40 \mathrm{msec}$ and were immediately followed by the mask, which was presented for $300 \mathrm{msec}$. The subjects were asked to try to identify each stimulus. There was a 9-sec interval between trials so that the subjects could write down their responses. A warning beep occurred $1 \mathrm{sec}$ before the onset of each target. The subjects received six practice trials prior to the test to familiarize them with the procedure. Each group received the same six practice words, which were unrelated to any of the study or test words.

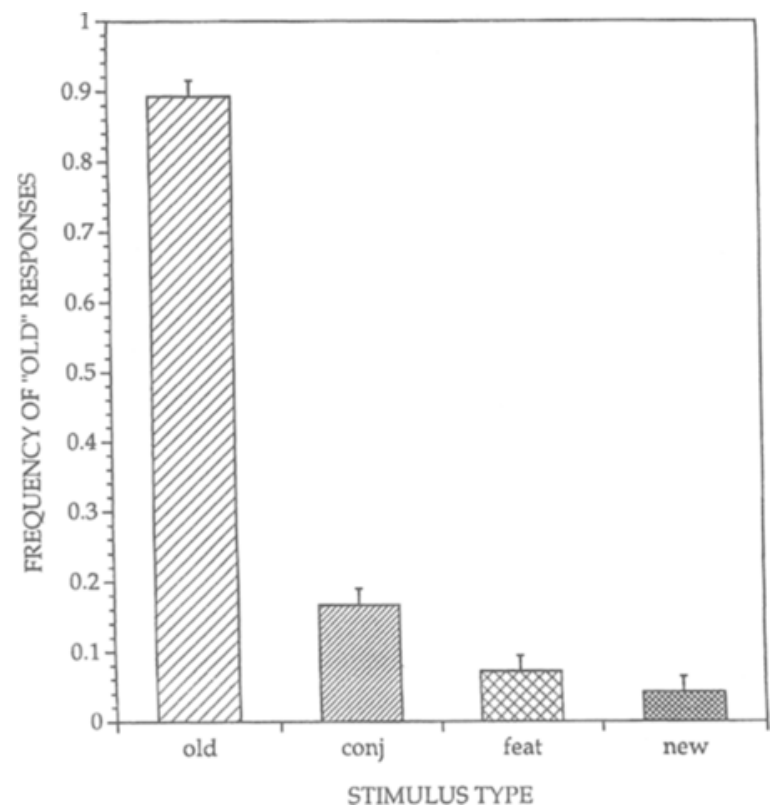

Figure 1. Mean proportion of "old" recognition responses for the four test conditions in Experiment 1 (conj, conjunction; feat, feature). The error bars represent the standard error of the difference between two means.

\section{Results and Discussion}

Recognition. The recognition results are presented in Figure 1. An analysis of variance (ANOVA) demonstrated that the number of "old" responses differed across the test conditions $[F(3,123)=318.043, p<.0001]$. To investigate the pattern among the means, we performed a series of planned comparisons by using orthogonal polynomials. There were, of course, more "old" responses for old stimuli than for conjunction, feature, and new stimuli $[t(123)=30.600, p<.0001]$. False alarms were more frequent for conjunction stimuli than for feature and new stimuli $[t(123)=3.974, p<.001]$. Finally, there were slightly more false alarms to feature than to new stimuli; however, the difference was not significant $[t(123)=$ $0.930, p>.15]$. The pattern of results is essentially identical to that obtained with our paradigm for sentences, nonsense words, and faces, and it supports our assertion that explicit memories for a broad variety of stimuli are constructed from an underlying set of stored parts.

Perceptualidentification. The results of the perceptual identification test are presented in Figure 2. The pattern of performance was quite different from the pattern observed for recognition. The test conditions again differed reliably $[F(3,123)=6.671, p<.001]$. We again performed three planned comparisons by using orthogonal polynomials and found that priming occurred only for old stimuli. Perceptual identification was better for old stimuli than it was for the other three stimulus types $[t(123)=4.302, p<.001]$. Performance for conjunction stimuli did not differ from performance for feature and new stimuli $[t(123)=-0.433, p>.3]$. Finally, the false alarm rates for feature and new stimuli did not significantly differ $[t(123)=-1.136, p>.1]$. These results indicate that the mechanisms that produce false alarms to conjunction stimuli are quite distinct from those that underlie perceptual identification, and they fail to support the proposal that the memories that produce priming in perceptual identification are constructed from parts. The results are therefore consistent with the proposal that a structural difference exists between implicit and explicit memories, which is more easily accounted for by a multiple-systems view than by an encoding-specificity explanation.

A closer examination of the data showed that the subjects responded with old words on about $22 \%$ of the conjunction trials and on about $15 \%$ of the feature trials. This indicates that when the subjects perceived an oldword fragment, they were biased to respond with an old word. Such an effect might result from implicit processes: Perceiving part of an old word might automatically bring the word to mind in much the same way that a fragment of an old word in a word-fragment-completion test causes the old word to come to mind. Alternatively, the subjects may have made intentional use of an explicit memory strategy on the perceptual identification task; that is, following each test presentation, they may have intentionally attempted to recollect the study words in 


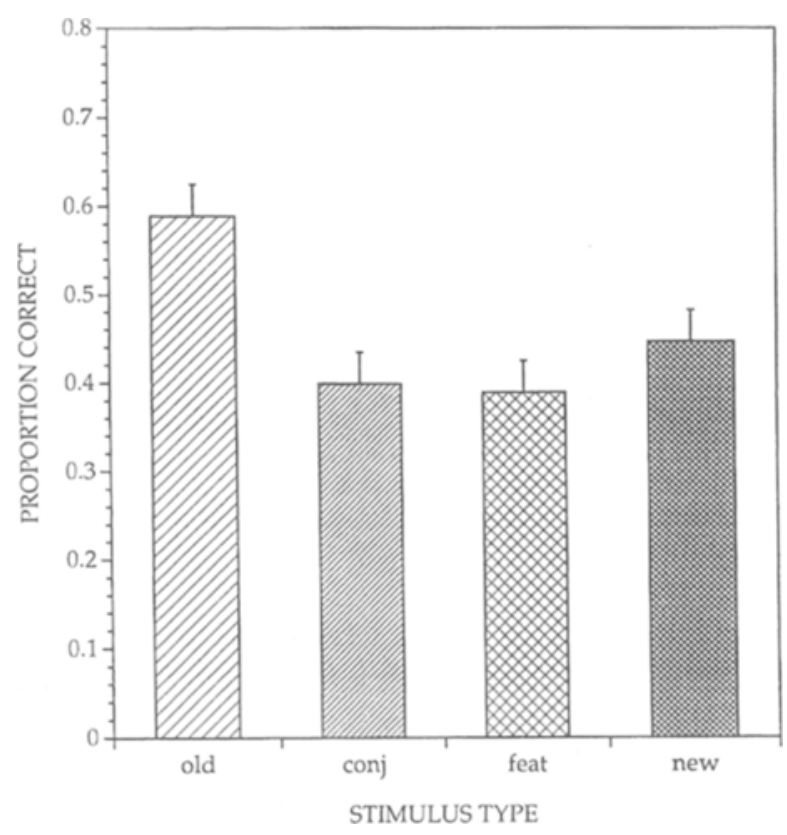

Figure 2. Mean proportion of correct perceptual identification responses for the four test conditions in Experiment 1 (conj, conjunction; feat, feature). The error bars represent the standard error of the difference between two means.

order to find the one that was the best match to the test word. Few of the subjects reported the use of such a strategy in postexperiment interviews. Indeed, many claimed that they failed to notice any relation between the study and test words. Additionally, such a strategy would be likely to produce poorer performance for conjunction than for feature words, since the subjects should be twice as likely to perceive an old-word part in a conjunction than in a feature word; we did not find such an effect. However, since the use of an explicit strategy could potentially mask a priming effect for conjunction stimuli, we decided to run another perceptual identification experiment. In Experiment 2, we tested whether priming occurs for conjunction words when subjects are prevented from intentionally utilizing explicit recollection in order to generate responses during the test.

\section{EXPERIMENT 2}

In Experiment 2, we tested whether priming occurs for conjunction words when there is no chance that subjects are intentionally attempting to generate test responses by recollecting previously presented study words. Only conjunction, feature, and new words were presented for perceptual identification. The subjects were informed before the start of the test that no previously studied words would be presented during the test and were also told to avoid responding with previously studied words, since such responses would be incorrect.

\section{Method}

Subjects. Forty-two Boston University undergraduates participated for credit in their introductory psychology classes. They were run in 14 groups of 3 subjects each. None of the subjects had participated in Experiment 1.

Stimuli and Apparatus. We used the stimuli and apparatus that were used in Experiment 1.

Design and Procedure. The design was identical to that of the perceptual identification portion of Experiment 1, except that no old stimuli were presented during the test. The subjects studied 16 words; the study orders were identical to those used in Experiment 1 . Following the filler task, the subjects were presented with 12 words in the perceptual identification test. The test orders were identical to the Experiment 1 test orders, except that old-word trials were omitted. As in Experiment 1, the subjects received six practice trials in the perceptual identification task. Before the start of the test, the subjects were told that none of the words that they had studied previously would be presented during the perceptual identification test and to avoid responding with old words, because those responses would be incorrect.

\section{Results and Discussion}

The subjects responded with old words on about $6 \%$ of conjunction trials, and on about $4 \%$ of feature trials. All of the subjects claimed that they had intentionally avoided responding with old words; these intrusions therefore represent failures of explicit recollection. The perceptual identification results are presented in Figure 3 . It is obvious from the graph that there was no effect of test condition $[F(2,82)=0.809, p=.45]$. An effect-size test confirmed that the independent variable accounted for essentially none of the total variance in the experiment, $\eta^{2}=.02$. Removing old stimuli from the test clearly did not result in a priming effect for conjunction stimuli.

Experiment 2 was identical to the perceptual identification portion of Experiment 1, except for the omission of old test stimuli. We therefore decided to directly test the effect of the presence of old test stimuli on performance in the other three test conditions by comparing performance in those conditions across the two experiments. A 2 (experiment) $\times 3$ (test condition) ANOVA failed to provide any evidence for an experiment $X$ test condition interaction $[F(2,164)=0.461, p=.63]$. It therefore does not appear that the presence of old stimuli in Experiment 1 exerted an effect on the pattern of means among the remaining test conditions. There was some evidence for a main effect of experiment; overall performance was slightly worse in Experiment 2 than in Experiment $1[F(1,82)=3.168, p=.08] .{ }^{1}$ Finally, despite the increased power that results from pooling data across the experiments, there was no evidence for a main effect of test condition $[F(2,164)=1.124, p=.33]$. Pooled over the experiments, the mean proportion of correct responses in the conjunction and new conditions was .35 and .37, respectively; the standard error of the difference between the means was .02. Together, the results of Experiments 1 and 2 demonstrate that priming in perceptual recognition occurs for old words, but not for conjunction words. 


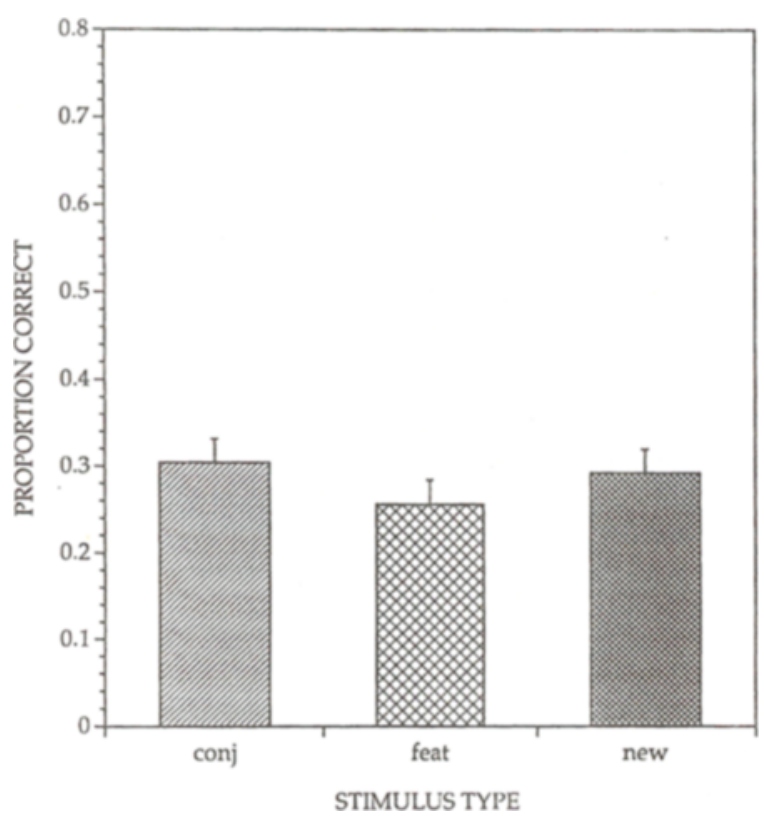

Figure 3. Mean proportion of correct perceptual identification responses for the three test conditions in Experiment 2 (conj, conjunction; feat, feature). Error bars represent the standard error of the difference between two means.

\section{EXPERIMENT 3}

Previous experiments by Reinitz and his colleagues as well as the recognition results of Experiment 1 provide ample evidence that subjects will make many more false alarms to conjunction stimuli than to feature or new stimuli on a recognition test. However, priming in perceptual identification occurs only for old stimuli. There are two important differences between recognition and perceptual identification tests. First, recognition is an explicit memory task, and perceptual identification is an implicit task. These divergent patterns of results may therefore indicate a fundamental difference between implicit and explicit memory in general. However, there is a second important difference between the tasks. Specifically, priming in perceptual identification reflects the facilitation provided by memory in on-line, rapid acquisition of perceptual information from stimuli. Such perceptual facilitation is not required in recognition, nor is it required in other implicit memory tests. It is therefore possible that the lack of priming for conjunction stimuli may be restricted to implicit tasks that are primarily perceptual; such priming may occur in implicit tasks that involve a strong conceptual component. Many authors have recently argued that word-fragment completion has a strong conceptual component that perceptual identification tests lack (e.g., Challis \& Brodbeck, 1992; Hirshman, Snodgrass, Mindes, \& Feenan, 1990). In Experiment 3 we tested whether priming occurs for conjunction stimuli in a word-fragment-completion test in order to distinguish between these alternatives. The design and procedure were similar to those of the previous experi- ments, except that we included an additional betweensubjects variable: the subjects had either 5 or $20 \mathrm{sec}$ to solve each word fragment. We included this manipulation to test the role of explicit recollection in word-fragment completion. Some authors (e.g., Challis \& Brodbeck, 1992) have proposed that word-fragment completion may be more vulnerable than perceptual identification to the use of intentional recollection during the test; that is, subjects might employ a generate-and-test strategy that makes extensive use of explicit recollection. Such a strategy should be much easier to employ in the 20 -sec condition than in the 5-sec condition. If priming for conjunction stimuli is a result of this strategy, we should observe different patterns of results for the two durations.

\section{Method}

Subjects. The subjects were 84 Boston University undergraduates who participated for credit in their introductory psychology classes. They were run in 28 3-subject groups. None of the subjects had participated in Experiments 1 or 2.

Stimuli and Apparatus. The study stimuli that were used in Experiments 1 and 2 were again used in Experiment 3. Fragments of the test stimuli used in the previous experiments were constructed by removing letters from the words and replacing them with underlines, with the restriction that there was only one possible solution for each fragment. The fragments and the study words were in the same font and were the same size.

Design and Procedure. The study procedure and filler task used in Experiments 1 and 2 were again used here. Two sets of 14 groups were run, using the same study and test orders that were used in Experiment 1. For 14 of the groups, test fragments were presented for $20 \mathrm{sec}$; for the remaining groups, fragments were presented for $5 \mathrm{sec}$. There was a $3-\mathrm{sec}$ interval between test fragments. The subjects attempted to solve the fragments and wrote down their re-

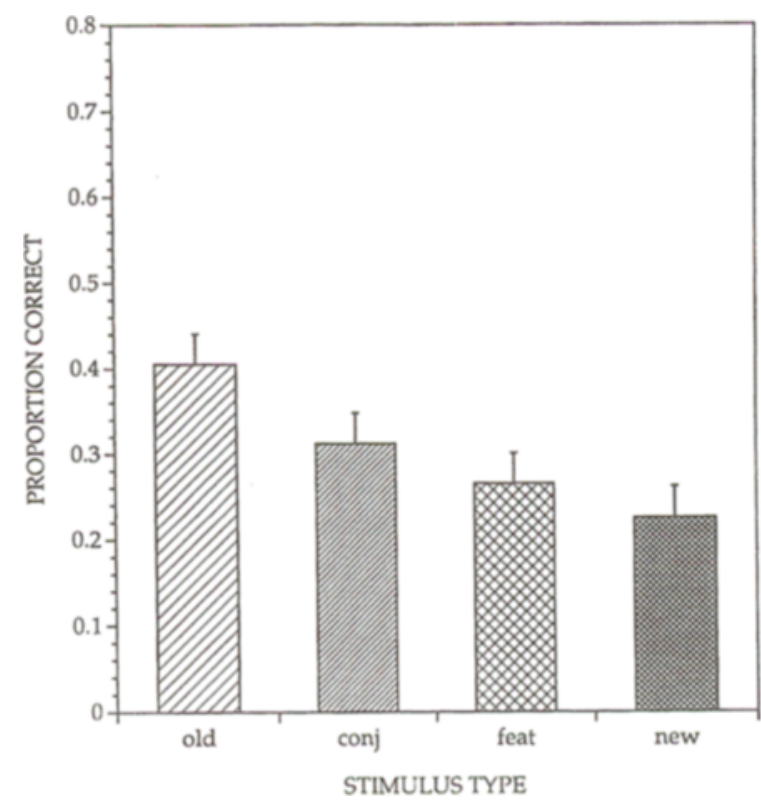

Figure 4. Mean proportion of correctly completed fragments for the four test conditions in Experiment 3 (conj, conjunction; feat, feature). The data are pooled over solution time, and the error bars represent the standard error of the difference between two means. 
sponses on an answer sheet. They first received six practice fragments to familiarize them with the task. These were fragmented versions of the practice words used in the other experiments.

\section{Results and Discussion}

Figure 4 shows the results pooled over solution time. The pattern of results is more similar to the pattern of results obtained for recognition than to the one obtained for perceptual identification. Correct responses in the four test conditions differed reliably $[F(3,249)=9.251$, $p<.0001]$. Three planned comparisons using orthogonal polynomials were performed to investigate the pattern of means. We replicated the standard word-fragmentcompletion priming effect: There were more correct responses to fragments of old words than to fragments of conjunction, feature, and new words $[t(249)=4.678$, $p<.001]$. In contrast to the perceptual recognition data, we also observed priming for conjunction stimuli: Performance was better for conjunction fragments than for feature and new fragments $[t(249)=2.156, p<.02]$. Finally, performance for feature and new stimuli did not differ significantly $[t(249)=1.082, p>.1]$.

Figure 5 shows the data separately for the two solution times. Overall performance was reliably poorer when the subjects had $5 \mathrm{sec}$ rather than $20 \mathrm{sec}$ to solve the fragments $[F(1,82)=19.537, p<.0001]$. However, the pattern of results is the same for the two conditions. Therefore, the priming that we observed for conjunction stimuli does not seem to be the result of intentional use of explicit recollection. In fact, nearly all of the subjects expressed surprise when they were informed following

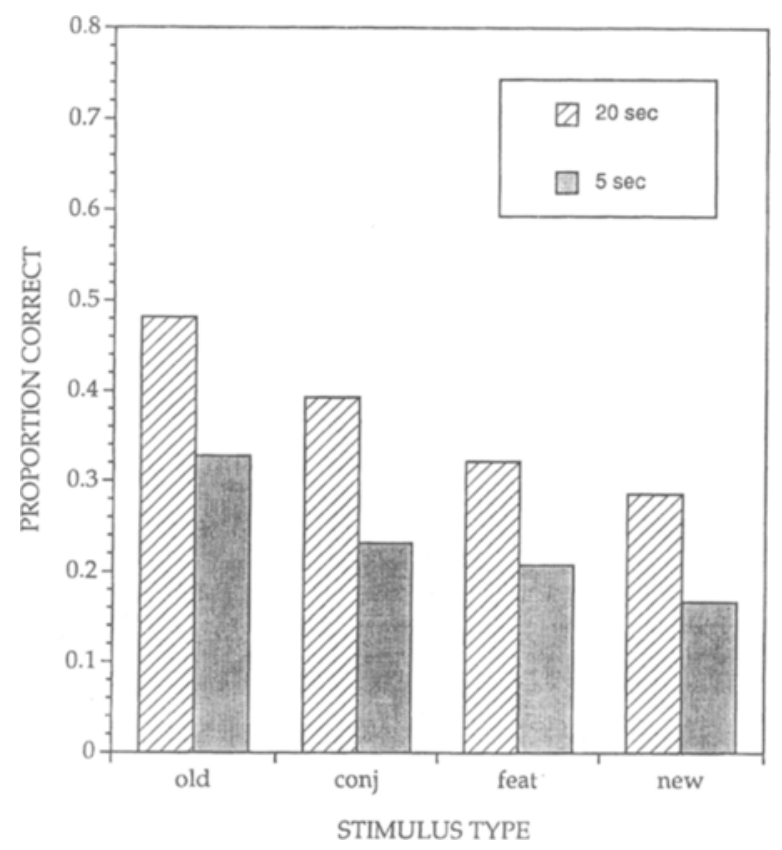

Figure 5. Mean proportion of correctly completed fragments for the four test conditions in Experiment 3 (conj, conjunction; feat, feature). Striped bars show the data for the 20-sec-exposure condition; solid bars show the data for the 5-sec-exposure condition. the experiment that some of the fragments were recombinations of previously viewed word parts. The absence of priming for conjunction stimuli that we observed for perceptual identification does not reflect a general property of implicit memory. Rather, such priming occurs on some implicit tasks, but not on others.

\section{GENERAL DISCUSSION}

\section{Summary of Results}

Experiment 1 demonstrated that subjects make more false alarms to compound words that are entirely constructed from parts of previously studied words than they do to partially and completely new stimuli. A different pattern of results was obtained when the memory test was perceptual identification rather than recognition. Although priming occurred for old words, there was no evidence of priming for conjunction words. Experiment 2 demonstrated that this lack of priming was not the result of a guessing strategy in which subjects generated responses by intentionally recollecting previously studied words. A comparison of the two perceptual identification experiments failed to provide any evidence that the presence of old test stimuli in Experiment 1 affected the pattern of results among the remaining test conditions; additionally, there was no evidence for priming in the conjunction condition, despite the increased power that resulted from pooling data across the experiments. Finally, Experiment 3 demonstrated a robust priming effect for conjunction stimuli in a word-fragment-completion test. The pattern of results was not affected by decreasing the time available to solve the fragments. It is therefore unlikely that priming resulted from a generate-and-test strategy that made extensive use of explicit recollection. The results imply that the memories that facilitated performance on our recognition and word-fragment-completion tasks were constructed from stored stimulus parts. It is therefore clear that evidence for an underlying parts structure is not unique to explicit tasks. The memories that facilitated performance on our perceptual identification task were apparently not constructed from parts that could be independently accessed during the task. This suggests that a structural difference exists between memories that facilitate on-line perception and memories that facilitate postperceptual processes.

\section{Role of Memory in Perception}

We observed priming for conjunction stimuli in recognition and word-fragment completion, but not in perceptual identification. The probable reason is that perceptual identification performance is to a large extent determined by how well the subject sees the test stimuli. Perceptual identification performance will therefore be influenced by factors that affect perceptual clarity. In the other tests, the perceptual clarity of the stimulus is not a factor in determining performance, since long exposure durations in these tasks ensure maximum perceptual clarity. The former case can essentially be re- 
duced to using memory in order to see; that is, information in memory can facilitate the construction of a perceptual representation. The latter cases can be reduced to seeing in order to remember; that is, once a perceptual representation of the stimulus has been constructed, it can provide access to memory representations of previously experienced stimuli. The current data indicate that perceptual memories, which facilitate perceptual clarity, may be structurally different from postperceptual memories, which can be accessed (either automatically or intentionally) on the basis of an intact perceptual representation that has already been constructed. Specifically, the former fail to show evidence of an underlying parts structure. Perceptual memories may therefore be holistic, template-like structures. This proposal is consistent with the notion of a presemantic, perceptual memory system proposed by Tulving and Schacter (1990), and is also consistent with findings indicating that perceptual identification performance is sensitive to small surface changes in the stimuli from study to test (e.g., Jacoby \& Hayman, 1987; Warren \& Morton, 1982). Finally, our proposal is consistent with Rajaram and Roediger's (1993) finding of cross-modal priming in word-fragment completion, but not in perceptual identification. The specific mechanism by which memory facilitates perception remains unclear; however, evidence suggests that memory can facilitate perceptual clarity by affecting the acquisition of information from test stimuli. Reinitz, Wright, and Loftus (1989) demonstrated that if exposure duration is held constant, more visual information is acquired from briefly presented photographs of objects and scenes when they are primed than when they are unprimed.

\section{Role of Perception in Memory}

Once a perceptual representation of a stimulus has been constructed, we propose that it can provide access to postperceptual memories. This access can be automatic and therefore implicit, as is sometimes the case in word-fragment completion. Alternatively, nonamnesic subjects can intentionally utilize perceptual information as a retrieval cue, as is the case in recognition tests. The current research indicates that intentionally and automatically accessed postperceptual memories share a common property - both are composed of parts that can be independently activated. This structural similarity implies that dissociations between tasks that require the activation of postperceptual memories may be well accounted for by a process-specificity framework. It is important to note that a memory may be postperceptual, in the sense that it plays no role in the construction of a perceptual representation during active on-line perception, and still represent perceptual attributes of a stimulus. Additionally, we do not mean to imply that the only means of accessing postperceptual memories in normal subjects is via the construction of a perceptual representation. It is well known that a myriad of items can serve as effective retrieval cues and that the effectiveness of a particular cue will depend on its relation to the way in which the information was originally encoded (e.g., Watkins \& Tulving, 1975).

\section{Concluding Comments}

We have provided empirical evidence to support the distinction between perceptual memories, which are involved in the construction of perceptual representations, and postperceptual memories, which are accessed following the construction of perceptual representations. We based this distinction on the finding that priming occurs only for old stimuli on tasks for which performance depends primarily on perceptual clarity, but for both old and conjunction stimuli on tasks in which memories are accessed from a preexisting, intact perceptual representation. The implication is that the latter, but not the former, memories are composed of parts that can be independently activated. If our proposal is correct, there are distinct and fundamentally different varieties of implicit memory. Perceptual memories function implicitly, in the sense that the top-down effects that they provide are automatic. Additionally, our results indicate that postperceptual memories may be accessed automatically on the basis of perceptual information. Thus, for any given task there are probably multiple automatic influences of memory; care must be taken to separate effects on perception from those on postperceptual processes.

\section{REFERENCES}

Brown, R., \& MCNEILL, D. (1966). The "tip of the tongue" phenomenon. Journal of Verbal Learning \& Verbal Behavior, 5, 325-337.

Challis, B. H., \& BRodbeck, D. R. (1992). Level of processing affects priming in word fragment completion. Journal of Experimental Psychology: Learning, Memory, \& Cognition, 18, 595-607.

Hirshman, E., Snodgrass, J. G., Mindes, J., \& Feenan, K. (1990). Conceptual priming in fragment completion. Journal of Experimental Psychology: Learning, Memory, \& Cognition, 16, 634-647.

JACOBY, L. L., \& HAYMAN, C. A. G. (1987). Specific visual transfer in word identification, Journal of Experimental Psychology: Learning, Memory, \& Cognition, 13, 456-463.

Kosslyn, S. M., Cave, C. B., Provost, D. A., \& von Gierke, S. M. (1988). Sequential processes in image generation. Cognitive Psychology, 20, 319-343.

Musen, G., \& SQuiRe, L. R. (1993). On the implicit learning of novel associations by amnesic patients and normal subjects. Neuropsychology, 7, 119-135.

RajaRAM, S., \& RoEDIGER, H. L., III (1993). Direct comparison of four implicit memory tests. Journal of Experimental Psychology: Learning, Memory, \& Cognition, 19, 765-776.

Reinitz, M. T., Lammers, W. J., \& Cochran, B. P. (1992). Memoryconjunction errors: Miscombination of stored stimulus features can produce illusions of memory. Memory \& Cognition, 20, 1-11.

Reinitz, M. T., Morrissey, J., \& DeMB, J. (1994). The role of attention in face encoding. Journal of Experimental Psychology: Learning, Memory, \& Cognition, 20 161-168.

Reinitz, M. T., Wright, E., \& LofTUs, G. R. (1989). Effects of semantic priming on visual encoding of pictures. Journal of Experimental Psychology: General, 118, 280-297.

ROEDIGER, H. L., III (1990). Implicit memory: Retention without remembering. American Psychologist, 45, 1043-1056.

Roediger, H. L., III, \& Blaxton, T. A. (1987). Effects of varying 
modality, surface features, and retention interval on priming in word-fragment completion. Memory \& Cognition, 15, 379-388.

Snodgrass, J. G., \& Luo, C. R. (1993, November). Components of information: A framew'or for memory research. Paper presented at the meeting of the Psychonomic Society, Washington, DC.

SQuire, L. (1992). Memory and the hippocampus: A synthesis from findings with rats, monkeys, and humans. Psychological Review, 99. 195-231.

Tulving, E., \& Schacter, D. (1990). Priming and human memory systems. Science, 247, 301-306

Warren, C., \& Morton, J. (1982). The effect of priming on picture recognition. British Journal of Psychology, 73, 117-129.
Watkins, M. J., \& Tulving, E. (1975). Episodic memory: When recognition fails. Journal of Experimental Psychology: General, $104,5-29$

\section{NOTE}

1. This trend is in the opposite direction from that expected if the lack of priming for conjunction stimuli in Experiment 1 were the result of a strategy based on intentional recollection. Such a strategy would lead to increased errors in the other test conditions; elimination of such a strategy would therefore be expected to improve performance.

\section{APPENDIX}

1. TOOTHPASTE HEARTACHE TOOTHACHE

5. EYELID WINEGLASS EYEGLASS

9. DOORKNOB DUMBBELL DOORBELL

13. PINWHEEL NEEDLEPOIN $\Upsilon$ PINPOINT

17. BIRTHRIGHT SOMEDAY BIRTHDAY

21. LIFESAVER SAILBOAT LIFEBOAT

25. SEAFOOD OFFSHORE SEASHORE
2. LIGHTWEIGHT ClubHOUSE LIGHTHOUSE
6. OVERSIGHT RAINCOAT OVERCOAT
10. COFFEEPOT CUPCAKE COFFEECAKE
14. MAILMAN CASHBOX MAILBOX
18. WINTERGREEN MEALTIME WINTERTIME
22. KEYNOTE BUTTONHOLE KEYHOLE
26. HORSEFLY SNOWSHOE HORSESHOE

3. CLASSWORK SHIPMATE CLASSMATE

7. BLACKTOP HEADBOARD BLACKBOARD

11. STARGAZE CATFISH STARFISH

15. TABLESPOON CHEESECLOTH TABLECLOTH

19. EVERYBODY ANYTHING EVERYTHING

23. EARTHQUAKE SILKWORM EARTHWORM

27. BOOKSHELF HALLMARK BOOKMARK

\section{HANDSTAND SHOTGUN HANDGUN \\ 8. NEWSWORTHY WASTEPAPER NEWSPAPER \\ 12. FOOTBRIDGE HARDBALL FOOTBALL}

16. FOREHEAD HINDSIGHT FORESIGHT

20. MASTERMIND MOUTHPIECE MASTERPIECE

24. SIDEWALK OUTLINE SIDELINE

28. BATHROBE BEDROOM BATHROOM 